\title{
Centrifuge Techniques and Apparatus for Transport Experiments in Porous Media
}

\section{ICPMG 2010}

E. D. Mattson

C. D. Palmer

R. W. Smith

M. Flury

U.S. Department of Energy

National Laboratory

operated by

Battelle Energy Alliance

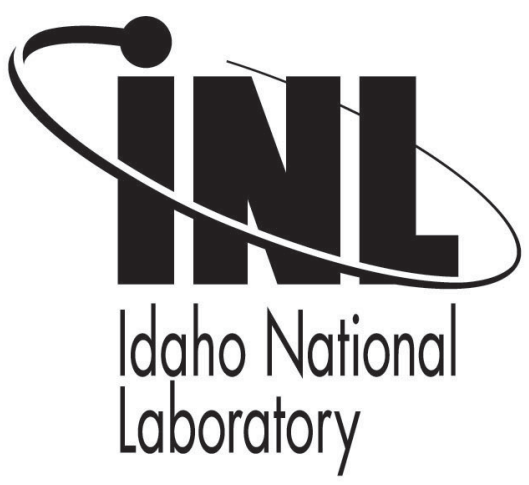

This is a preprint of a paper intended for publication in a journal or proceedings. Since changes may be made before publication, this preprint should not be cited or reproduced without permission of the author. This document was prepared as an account of work sponsored by an agency of the United States Government. Neither the United States Government nor any agency thereof, or any of their employees, makes any warranty, expressed or implied, or assumes any legal liability or responsibility for any third party's use, or the results of such use, of any information, apparatus, product or process disclosed in this report, or represents that its use by such third party would not infringe privately owned rights. The views expressed in this paper are not necessarily those of the United States Government or the sponsoring agency. 


\title{
Centrifuge Techniques and Apparatus for Transport Experiments in Porous Media
}

\author{
E.D. Mattson \& C.D. Palmer \\ Idaho National Laboratory, Idaho Falls, Idaho, USA
}

R.W. Smith

University of Idaho, Idaho, Idaho Falls, USA

M. Flury

Washington State University, Pullman, Washington, USA

\begin{abstract}
This paper describes experimental approaches and apparatus that we have developed to study solute and colloid transport in porous media using Idaho National Laboratory's 2-m radius centrifuge. The experimental techniques include water flux scaling with applied acceleration at the top of the column and subatmospheric pressure control at the column base, automation of data collection, and remote experimental control over the internet. These apparatus include a constant displacement piston pump, a custom designed liquid fraction collector based on switching valve technology, and modified moisture monitoring equipment. Successful development of these experimental techniques and equipment is illustrated through application to transport of a conservative tracer through unsaturated sand column, with centrifugal acceleration up to 40 gs. Development of such experimental equipment that can withstand high accelerations enhances the centrifuge technique to conduct highly controlled unsaturated solute/colloid transport experiments and allows in-flight liquid sample collection of the effluent.
\end{abstract}

\section{INTRODUCTION}

The selection and design of subsurface environmental restoration strategies (including monitored natural attenuation) frequently relies on the use of sophisticated numerical models that couple transport and biogeochemical processes to predict the fate and transport of contaminants and introduced remediation agents in heterogeneous subsurface media. These models are typically validated by comparing modeling results to 'large-scale' field research demonstrations and 'small-scale' laboratory experiments. Although controlled field experiments have the advantage of being representative of the field-scale problem, such experiments are costly, difficult to conduct, limit the use of relevant contaminants, and offer little direct control over boundary conditions. Conversely, laboratory column experiments, which are generally inexpensive and better controlled, are of limited value because they do not closely mimic field conditions. Reactive transport studies conducted in unsaturated porous media compounds these limitations due to the extensive length of time need to transport a tracer through the porous media (e.g. up to 300 days in laboratory sand packed column experiments [Jardine et al. 1993a, b]). Experi- ments conducted on large centrifuges can help bridge the gap between field and lab experiments because the experimental packages are large enough to incorporate critical field-scale conditions. They can also significantly reduce the time necessary for unsaturated transport experiments because flow rates through the porous media can be controlled at prescribed moisture content conditions.

A mathematical description of a steady-state, unsaturated flow field in a centrifuge has been described by Nimmo et al. (1987). Numerous authors have presented scaling laws for water flow and solute transport in centrifuge experiments (e.g., Garnier et al., 2000). These scaling relationships allow us to design experiments where we can increase the velocity of water through the sample while maintaining moisture potential and water content essentially unaffected. This increases solute advection reduces the time necessary for vertical flow experiments; for example, a solute transport experiment that might take a year to conduct on the bench top could be completed in a week in a centrifuge operating at 50gs.

Although commercially available cabinet-size centrifuges (Conca and Wright 1990, 1998, Gamerdinger and Kaplan 2000) have been used to evaluate miscible solute transport in unsaturated soil, their 
application is limited to small samples $(5.2 \mathrm{~cm}$ length $x 3.3 \mathrm{~cm}$ diameter or $\sim 45 \mathrm{~cm}^{3}$ ) of homogeneous materials. In addition, most small centrifuges are limited to simplistic controlled flux application at the surface and free drainage at the lower boundary and lack in-flight monitoring of moisture contents, pressures and solute concentrations. Measurements of these variables are physically acquired after stopping the centrifuge.

Large centrifuges overcome many of the limitations of the cabinet-size centrifuge in conducting solute transport experiments in unsaturated soils. Advantages include large sample sizes (both in diameter and length), better experimental control of the boundary conditions, in-flight monitoring of the state variables, and multi-dimensional testing. CCD cameras can be mounted and used to monitor the movement of non-aqueous phase liquids (NAPL) and dyes, and record other changes in the experimental system. Flow-through conductivity cells can be mounted in the system (e.g., Hensley and Savvidou, 1993) to obtain in-flight tracer breakthroughcurves. Fraction collectors (see Methods section) can be added to collect effluent samples for subsequent chemical analyses.

The addition on computers on the hub of large centrifuge systems essentially permit "bench-scale" type experiments to be conducted under enhanced accelerations with fully automated control. At the Idaho National Laboratory (INL), we have developed tools and techniques to conduct flux controlled unsaturated solute transport experiments with collection of the column effluent while in-flight. This advancement in automation and control extends the

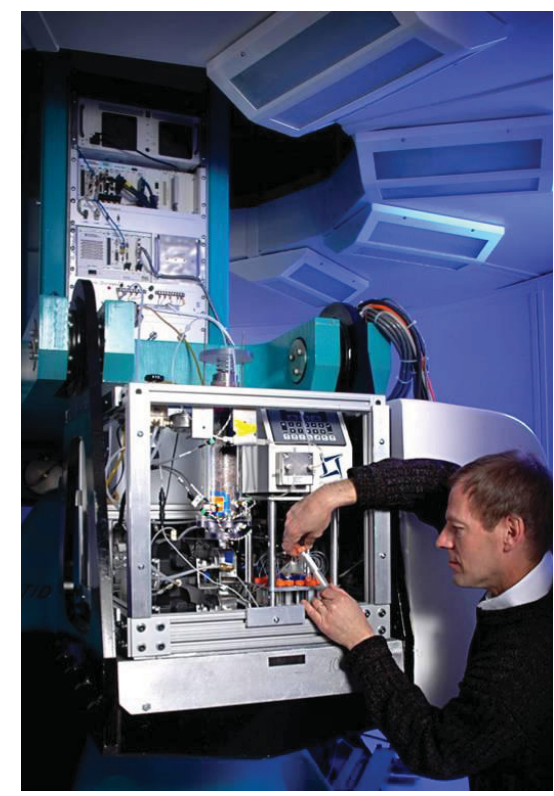

Figure 1. Photograph of the experimental package installed on the platform of the INL 2-meter centrifuge. Note the column (center), solute tank (upper left), pump (upper right). and effluent sampling svstem (lower right). limits of miscible solute transport in unsaturated soils to solute concentrations that better represent those in the prototype. This paper describes the equipment and controls necessary to conduct such experiments and verifies its applicability using a one-dimensional sand-packed column experiment conducted over a range of centrifugal acceleration.

\section{IDAHO NATIONAL LABORATORY CENTRIFUGE FACILITY}

The Idaho National Laboratory centrifuge is a 2-m radius, 50 g-tonne Actidyn Systemes model C61-3 centrifuge (Figure 1) that can carry an experimental package as large as $70 \mathrm{~cm}$ long by $50 \mathrm{~cm}$ thick by 60 $\mathrm{cm}$ high and $500 \mathrm{~kg}$ mass at accelerations up to 130 $\mathrm{g}$ (Smith et al. 2002). An experimental package is built in a cage-like aluminum support structure that both supports the experiment and provides secondary containment in case of leakage or failure.

In-flight experimental control and monitoring of experiments is accomplished using a data acquisition system employing a wireless network hub. The hub links computers in the control room with National Instruments data acquisition systems mounted directly on the centrifuge. Real-time monitoring data is collected using LabVIEW software and stored and displayed on control room computers where collaborating researchers can access the data via the web.

\section{METHODS}

Tracer experiments through unsaturated soil are typically conducted by packing a column with soil, applying a solution to the surface until a steady-state flow field is established through the column, switching the background solution to one that contains a tracer, and measuring the tracer concentration as a

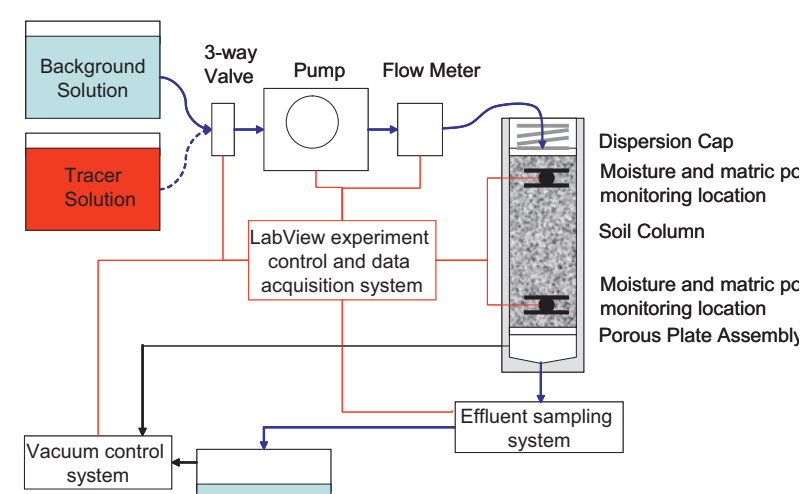

Figure 2. A schematic illustrating the major experimental components of solute transport experiments through unsaturated porous media. 
function of time at the bottom of the soil column.

The experimental setup is illustrated in Figure 2. Two tanks under atmospheric pressure contain a 330-ppm KBr background solution and a 2000-ppm $\mathrm{KBr}$ tracer solution. A solenoid 3-way valve controls which of the solutions is pumped to the column. A remotely controlled Encynova pump (model 2-4) is used to adjust the flow rate to the top of the soil column. An experiment is conducted by placing the experimental package on the centrifuge platform and spinning the centrifuge at a constant speed to obtain the desired centrifugal acceleration. The 3-way valve is set to the 330-ppm $\mathrm{KBr}$ background solution and a constant flux is delivered to the top of the column via the pump. A constant vacuum is applied to the effluent collection system at the base of the soil column. The vacuum is adjusted until the monitoring equipment (capacitance probes and tensiometers) indicates that the water flux through the soil column is in steady state. At this time, the 3-way valve is switched to the 2000-ppm $\mathrm{KBr}$ tracer solution and the fraction collector is activated to collect discrete effluent samples at a predetermined rate.

The test column is constructed from a $5.7-\mathrm{cm}$ diameter by $28-\mathrm{cm}$ long multi-piece Lexan cylinder (Figure 3) and packed with a 2-to $0.075-\mathrm{mm}$ diameter sandy soil. At the top of this test column, a cap with a porous stone diffuser was used to spread the input solution over the surface of the column. The cap was not rigidly attached to the column but was pressed against the soil surface using a large compression spring, to ensure good contact with the soil. The moisture content and matric potential were monitored in the soil column at two locations approximately $4.5 \mathrm{~cm}$ from each end. Soil moisture was measured using a Decagon Echo 10 probe, where the electrodes have been modified to wrap around the inner circumference of the experimental column (Mattson et. al. 2006). Small 0.5-cm diameter porous ceramic cups were attached to Honeywell 26PCCFA6D pressure transducers ( 0 to $15 \mathrm{psi}$ range) to measure the soil matric potential. The bottom of the column was set as a constant pressure boundary using a Versapor $1.2 \mathrm{um}$ diameter filter supported by a porous stone between the soil and the lower fluid collection chamber. A constant vacuum was applied to the lower fluid collection chamber.

The experiment is remotely controlled and monitored using a computer program written using LabVIEW software. This program controls the 3-way valve switching of the influent background and tracer application, the pump rate, and the effluent collection system. Monitoring of the experiment is also accomplished using LabVIEW programs. Influent water flow rate, soil moisture, soil matric potential, applied vacuum at the lower boundary, and the effluent electrical conductivity can all be monitored at a user specified interval. Influent flow rates are recorded using a Sensirion ASL-1430-24 liquid mass flow meter capable of measuring rates as low as 150 $\mathrm{nL} \mathrm{min}^{-1}$. The lower boundary vacuum is controlled by adjusting the pressure of air supplied through the centrifuge rotary joint to a venturi vacuum pump (Cole-Parmer) mounted on the rotating centrifuge. The vacuum is monitored using a Honeywell pressure transducer (26PCCFA6D, 0 to 15 psi range). Electrical conductivity of the effluent solution was measured using a Microelectrode (model 16-900) flow-thru conductivity electrode.

When samples are required for chemical analyses, the method has been to periodically stop the centrifuge to physically remove an effluent sample (e.g., Antoniadis and McKinley, 2000). A better approach is to collect samples in flight, however commercially available fraction collectors fail to operate on the centrifuge due to their inability to physically operate at high accelerations. Due to this failure, we designed and built an effluent sampling system capable of working in our centrifuge experiments (Figure 4). A fundamental difference between our sampling system and commercially available fraction collectors is the reliance on valves and air pressure to move fluids to stationary sample vials rather that attempting to move the sample vials. Column effluent is allowed to fill a sample accumulation connection tube between two large bore stainless steel 3-way valves (Figure 4a). Once the effluent valve connection tube is full, effluent flows into a waste container. To collect a sample, both valves are activated (Figure 4B). When in the ' $\mathrm{B}$ ' position, the top valve isolates the column from the effluent collection chamber and the bottom valve isolates the collection tube from the waste container. Pressurized air is used to transport the effluent in the collection tube to a 26-port
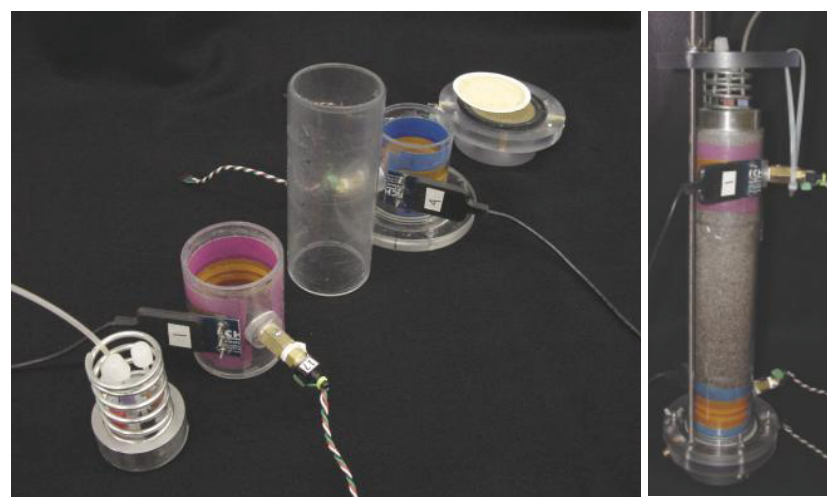

Figure 3. Multi-piece lexan column used for 1 dimensional solute transport experiments. A key feature of the columns is the installed capacitance water content probes and the mini tensiometers. 


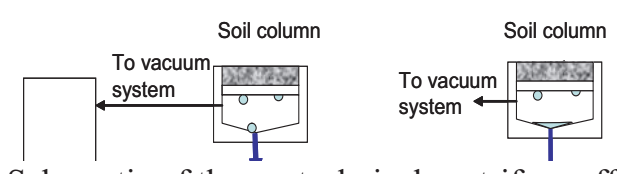

Figure 4. Schematic of the geotechnical centrifuge effluent collection system.

porous media

switching valve connected to $15-\mathrm{ml}$ sample collection vials (Figure 5 ). With the valves in the ' $\mathrm{B}$ ' position, effluent from the column accumulates above the upper 3-way valve. After a sufficient time has passed to empty the accumulation tube, the valves switch back to their original position to collect the next sample. Valve switching is performed via a

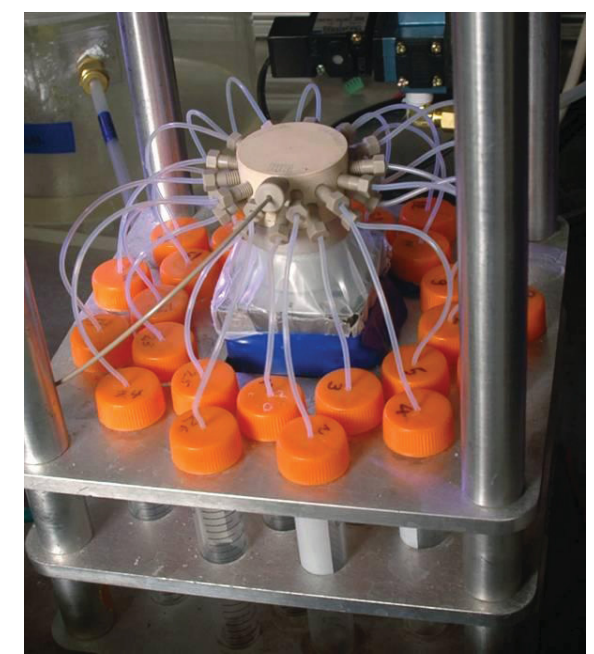

Figure 5. Photograph of the centrifuge effluent collection system (shown schematically in Figure 4b). Note the 26 position high pressure rotor valve (center).

LabVIEW program that allows automated operation of the effluent collection for subsequent laboratory analyses. Timing of the sample collection is operator controlled. Multiple 26-port switching valves can be daisy-chained together to allow additional samples to be collected.

\section{RESULTS AND DISCUSSIONS}

The experimental design and equipment was tested in a series of preliminary experiments to verity the establishment of a one-dimensional flow field at high accelerations and that the tracer output could be accurately measured. To confirm that flow was effectively unidirectional through out the column, red dye was added to the tracer solution for one test. The test was conducted similar to a normal tracer experiment except the test was stopped when the red dye nearly reached the end of the column. Subsequent visual inspection of the dye distribution at the top of the soil surface confirmed that there is sufficient capillary dispersion in the porous stone to evenly spread the influent across the top of the soil. Subsequent destructive sampling of the column indicated an even red staining of the sand throughout the column.

A second equipment test was conducted to evaluate the comparability of solute break through curves determined by the in-flight electrical conductivity cell and post-experimental analysis of bromide concentration. Our results suggest a good correspondence between the breakthrough curves derived from the conductivity measurements and the $\mathrm{Br}$ - concentrations determined by ion chromatograph (Dionex DX-320) analysis of collected effluent samples (Figure 6). A single value for the velocity $\left(0.13 \mathrm{~cm} \mathrm{~min}^{-}\right.$ $\left.{ }^{1}\right)$ and the dispersion coefficient $\left(0.040 \mathrm{~cm}^{2} \mathrm{~min}^{-1}\right)$ were estimated using a non-linear parameter estimation spreadsheet program and an analytical solution to the convection-dispersion equation (Wraith and Or 1998). The breakthrough curves calculated from these values describe both the normalized bromide effluent samples and the normalized conductivity measurements. This result suggests that for the experiments involving only the $\mathrm{KBr}$ tracers described in this report, breakthrough curves derived from the easier-to-collect continuous electrical conductivity measurements are reflective of breakthrough curves collected using the effluent sampling system and that breakthrough curves can be defined solely from the in-line conductivity measurements. Experiments using multiple reactive and/or conservative tracers would, however, require the use of the effluent sam-

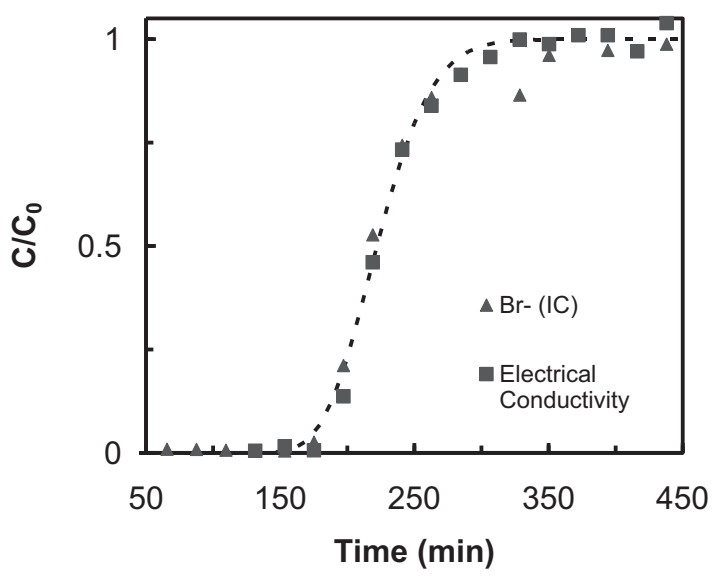

Figure 6. Breakthrough curve showing the correspondence between real time in line electrical conductivity measurements and post-experiments analyses of $\mathrm{Br}^{-}$by ion chromatography. 
pling system and subsequent post-experimental chemical analysis.

Success of the equipment testing experiments gave confidence that tracer transport experiment in unsaturated soil could be conducted on the INL centrifuge at 1, 10, 20, 30, and 40 times earth's gravitational acceleration. Since the vertical flux of water through soil is dependent on the body force experienced by the water, the applied water flux should therefore be proportional to the applied centrifugal acceleration. Adjusting the flow rate leads to an advantage of using a centrifuge for unsaturated solute transport experiments; the time required to conduct an experiment can be decreased by increasing the applied acceleration. Comparison of breakthrough results from experiments conducted on the centrifuge at $1 \mathrm{~g}$ to $40 \mathrm{~g}$ is illustrated in Figure $7 \mathrm{a}$. Although not exactly inversely proportional to applied acceleration (discussed later), the 40-g experiment required significantly less time to achieve breakthrough $\left(\mathrm{C} / \mathrm{C}_{0}=0.5\right)$ when compared with the $1 \mathrm{~g}$ experiment.

To analyze these data sets, time is normalized using the applied flux and the column moisture content from each experiment, then the data are plotted in

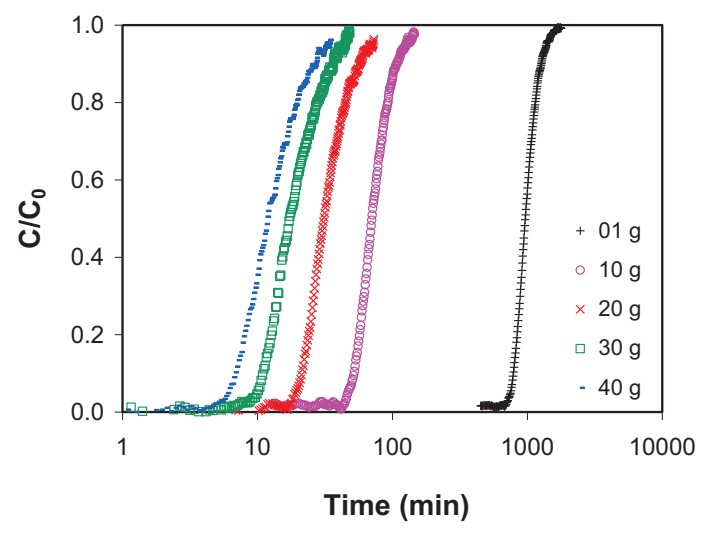

a)



b)

Figure 7. Comparison of breakthrough curves for 1, 10, 20, 30 and 40-g column experiments in terms of experimental time (upper, 7a) and pore volume (lower, 7b). terms of pore volume (e.g., dimensionless time). The normalized breakthrough curves for experiments conducted at $1,10,20,30$, and 40 g respectively are shown in Figure $7 \mathrm{~b}$. The average pore-water velocity, dispersion coefficient, moisture content and breakthrough time (at $\mathrm{C} / \mathrm{C}_{0}=0.5$ ) calculated from these breakthrough curves using a non-linear parameter estimation spreadsheet program (Wraith and Or 1998) are presented in Table 1 . The parameter $\mathrm{N}$ is the dimensionless applied acceleration and is calculated by dividing the centrifugal acceleration by earth's gravity. The applied water flow rate through the column was adjusted based on a simple linear scaling with $g$ in an attempt to maintain the same water content in all experiments. Although mostly successful, the measured water content of the column decreased with increasing N, likely due to nonlinear competition between gravitational (scaled in centrifuge experiments) and capillary (not scaled in centrifuge experiments) forces.

The time of arrival of the $\mathrm{C} / \mathrm{C}_{0}=0.5$ relative concentration at the effluent end of the column increases linearly with $1 / \mathrm{N}$ (Figure 8 ). Although the variability of water content in the column tests is relatively small (0.090 to 0.187 , Table 1$)$, there is a significant variation with $\mathrm{N}$. The hydraulic conductivity of the unsaturated soil is a function of the moisture content and since the measured moisture content is not exactly the same between the experiments, the solute transport results will deviate some of the scaling relationships. For example, the time for the breakthrough $\left(\mathrm{C} / \mathrm{C}_{0}=0.5\right)$ at $\mathrm{N}=10$ is not exactly twice the time for breakthrough at $\mathrm{N}=20$ (see Table 1). Extrapolation of a regression through the 10 to $40 \mathrm{~g}$ breakthrough times to $1 \mathrm{~g}$ results in a breakthrough time of 808 minutes, approximately 20 percent less that the measured value.

A second important parameter that is calculated from these experiments is the dispersion coefficient. Culligan and Savvidou (1995) calculated the dispersion coefficient as

$$
D=D_{m}+\alpha N v
$$

where $D_{m}$ is the effective diffusion coefficient in the

Table 1. Parameters derived from breakthrough curves data

\begin{tabular}{llllll}
\hline \hline $\mathrm{N}$ & $\begin{array}{l}\mathrm{Q} \\
\mathrm{mL} / \mathrm{min}\end{array}$ & $\begin{array}{l}\mathrm{V} \\
\mathrm{cm} / \mathrm{min}\end{array}$ & $\begin{array}{l}\text { D } \\
\mathrm{cm}^{2} / \mathrm{min}\end{array}$ & $\begin{array}{l}\left(\mathrm{C} / \mathrm{C}_{0}=0.5\right) \\
\min \end{array}$ \\
\hline \hline 1 & 0.014 & 0.0292 & 0.015 & 0.187 & 993 \\
10 & 0.14 & 0.3974 & 0.51 & 0.137 & 73.0 \\
20 & 0.28 & 0.892 & 2.19 & 0.122 & 32.5 \\
30 & 0.42 & 1.528 & 6.2 & 0.103 & 18.3 \\
40 & 0.56 & 2.416 & 12.1 & 0.090 & 12.0
\end{tabular}




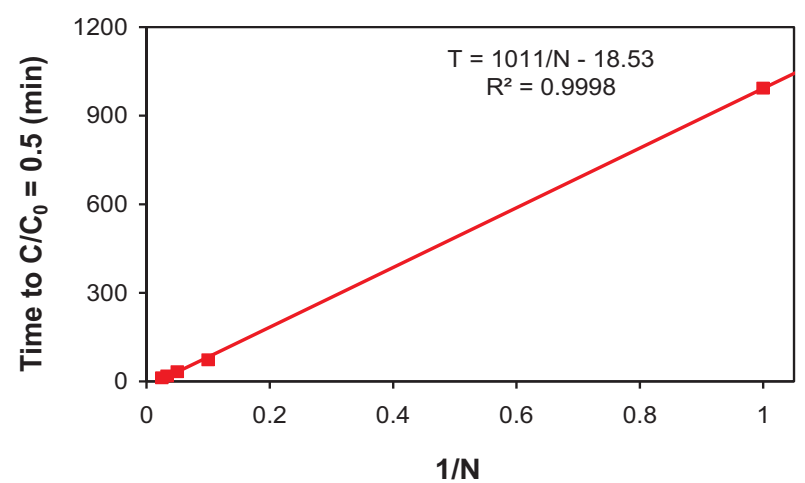

Figure 8. Arrival times for the $\mathrm{C} / \mathrm{C}_{\mathrm{o}}=0.5$ relative concentration at the effluent end of the column.

porous medium and $\alpha$ is the dispersivity. In our results since the velocity is a linear function of $\mathrm{N}$, it follows that $\mathrm{D}$ varies with $\mathrm{N}^{2}$. A plot of $D$ versus $\mathrm{N}$ $\mathrm{v}$ (Figure 9) yields a straight line suggesting that the experimental apparatus on the centrifuge is operating correctly.

\section{CONCLUSIONS}

The improved moisture probes, new fraction collector, and general experimental setups developed at the INL represent significant advancements in the techniques needed to conduct in-flight sampling and monitoring on the centrifuge. The centrifuge allows experiments to be completed more quickly than tests conducted at 1-g, and permits experiments to be conducted under a range of conditions that would be difficult or impossible using conventional approaches. Despite some deviation in the moisture content between experimental runs, the transport parameters could be scaled to the $1 \mathrm{~g}$ tests using previously published scaling laws. Our ability to control the upper and lower boundary of the experiment and collect effluent samples for subsequent analyses allows for realistic solute transport experiments in unsaturated

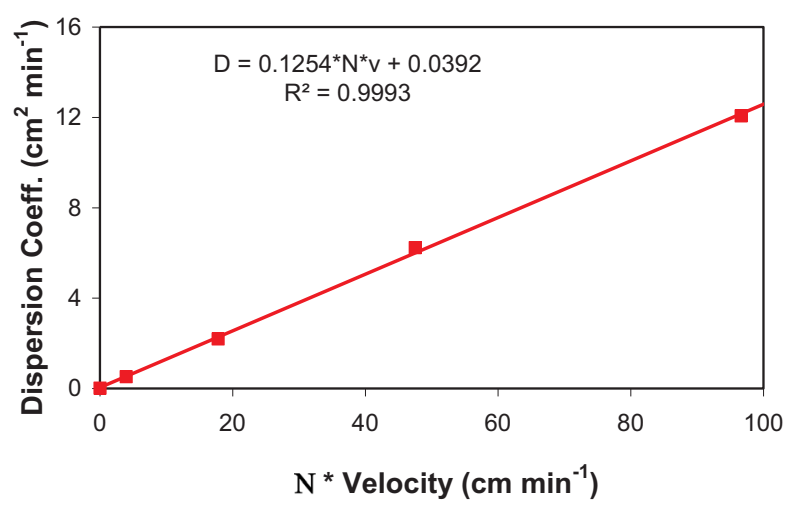

Figure 9. A plot of D vs Nv yields a straight line with a slope of $0.125 \mathrm{~cm}$ and an intercept of $0.039 \mathrm{~cm}^{2} \mathrm{~min}^{-1}$. soils to be conducted in a centrifuge.

Disclaimer. Commercial products named in this article are for the reader's reference and do not represent endorsement by the INL.

Work supported by the U.S. Department of Energy, Office of Environmental Management, under DOE Idaho Operations Office Contract DE-AC07-05ID14517.

\section{REFERENCE:}

Antoniadis, V., and J.D. McKinley. 2000: "Leaching tests in a laboratory centrifuge on zinc migration in london clay," International Symposium on Physical Modelling and Testing in Environmental Geotechnics, La Baule, J. Garnier, L. Thorel, E. Haza, LCPC (eds), pp. 53-60.

Conca, J.L. \& Wright, J.V. 1990. Diffusion coefficients in gravel under unsaturated conditions, Water Resour. Res., 26:1055-1066.

Conca, J.L. \& Wright, J.V. 1998. The UFA Method for Rapid, Direct Measurements of Unsaturated Soil Transport Properties, Australian J. of Soil Research, 36:291-315.

Culligan-Hensley, P.J. \& Savvidou, C. 1995. Environmental geomechanics and transport processes, in Geotechnical Centrifuge Technology, RN Taylor (ed.), Chapman and Hall, London, pp. 196-263.

Gamerdinger, A.P. \& Kaplan, D.I. 2000. Application of a continuous-flow centrifugation method for solute transport in disturbed, unsaturated sediments and illustration of mobileimmobile water, Water Resour. Res., 36:1747-1755.

Garnier, J., L. Thorel, E. Haza, LCPC (eds), International Symposium on Physical Modelling and Testing in Environmental Geotechnics, La Baule, pp. 191-260.

Hensley, P.J. and C. Savvidou. 1991, "Modelling coupled heat and contaminant transport in groundwater", Int. J. Numerical Anal. Meth. Geomech. 17, 493-527.

Jardine, P.M., Jacobs, G.K., \& O’Dell, J.D. 1993a. Unsaturated transport processes in undisturbed heterogeneous porous media: II. Co-contaminants, Soil Sci. Soc. Am. J. 57:954962.

Jardine, P.M., Jacobs, G.K., \& Wilson, G.V. 1993b. Unsaturated transport processes in undisturbed heterogeneous porous media: I. Inorganic contaminants, Soil Sci. Soc. Am. J. 57:945-953.

Mattson, E.D., Baker, K.E, Palmer, C.D, Breckenridge, C.R, Svoboda, J.M, \& Smith, R.W. 2006. A Flexible Water Content Probe for Unsaturated Soil Column Experiments, $\mathrm{Va}$ dose Zone Journal 5:805-808.

Nimmo, J.R., J. Rubin, and D.P Hammermeister, Unsaturated flow in a centrifugal field: Measurement of hydraulic conductivity and testing of Darcy's law, Water Resour. Res., 23, 124-134, 1987.

Smith, R.W., Payne, S.J., \& Miller, D.L. 2002. INEEL Environmental Geocentrifuge Facility Developments. In R. Phillips, P.J. Guo, and R. Popescu (eds.), Physical Modeling in Geotechnics: ICPMG '02, A.A. Balkema Publishers, Lisse, The Netherlands, pp. 55-58.

Wraith, J.M., \& Or D. 1998. Nonlinear parameter estimation using spreadsheet software. J. Nat. Resour. Life Sci. Educ. $27: 13-19$ 